\title{
Neurological Disturbances, Premature Lethality, and Central Myelination Deficiency in Transgenic Mice Overexpressing the Homeo Domain Transcription Factor Oct-6
}

\author{
Niels A. Jensen, ${ }^{\star}$ Karen M. Pedersen, ${ }^{*}$ Julio E. Celis, ${ }^{\star}$ and Mark J. West ${ }^{\ddagger}$ \\ $*$ Department of Medical Biochemistry and ${ }^{\ddagger}$ Department of Neurobiology, University of Aarhus, 8000 Aarhus C, Denmark
}

\begin{abstract}
Pit, Oct, Unc (POU) homeo domain transcription factors have been implicated in various developmental processes, including cell division, differentiation, specification, and survival of specific cell types. Although expression of the transcription factor Oct-6 in oligodendroglia is confined to the promyelin stage and is downregulated at the myelin stage of development, the effect of Oct-6 overexpression on oligodendrocyte development has not been established. Here we show that transgenic animals overexpressing Oct-6 at late oligodendrocyte development develop a severe neurologic syndrome characterized by action tremors, recurrent seizures, and premature death. Axons in the central nervous system of Oct-6 transgenics were hypomyelinated, hypermyelinated, or dysmyelinated, and ultrastructural analyses suggested that myelin formation was premature. The vulnerability of developing oligodendroglia to Oct-6 deregulation provides evidence that the POU factor may play a direct role in myelin disease pathogenesis in the mammalian CNS. (J. Clin. Invest. 1998. 101:1292-1299.) Key words: Tst-1 • SCIP • myelin basic protein $\bullet$ hypomyelination
\end{abstract}

\section{Introduction}

Myelin is a laminar membranous structure, laid down in segments around selected nerve fibers, that increases the velocity of action potentials (1-5). The myelin of the central nervous system $(\mathrm{CNS})^{1}$ is synthesized by oligodendroglia that comprise a population of structurally heterogeneous cells present mainly in the white matter (6). In the corpus callosum and the optic nerve, a single oligodendrocyte typically myelinates between 5 and 20 axonal internodes, whereas a one-to-one relationship is often observed in large axons of the spinal cord $(7,8)$. Myeli-

Address correspondence to Niels A. Jensen, Ph.D., Department of Medical Biochemistry, University of Aarhus, 8000 Aarhus C, Denmark. Phone: +45-89-42-28-79; FAX: +45-86-13-11-60; E-mail:naj@ biobase.dk

Received for publication 23 September 1997 and accepted in revised form 8 January 1998.

1. Abbreviations used in this paper: CNS, central nervous system; MBP, myelin basic protein; PLP, proteolipid protein; PNS, the peripheral nervous system; POU, Pit, Oct, Unc; TdT, terminal deoxynucleotidyl transferase; TUNEL, TdT-mediated dUTP-biotin nick end labeling.

J. Clin. Invest.

(C) The American Society for Clinical Investigation, Inc. 0021-9738/98/03/1292/08 \$2.00

Volume 101, Number 6, March 1998, 1292-1299

http://www.jci.org nation of the peripheral nervous system (PNS) is accomplished by Schwann cells, which invariably myelinate axons in a oneto-one relationship $(9,10)$.

Pit, Oct, Unc (POU) transcription factors are expressed in the nervous system of species as diverse as worms and mammals, and they have been implicated in various developmental processes ranging from regulation of cell division and differentiation to specification and survival of particular neuronal subtypes (11-13). POU proteins contain a highly conserved bipartite domain of 150-160 amino acids consisting of a 75-82 amino acid POU-specific domain, a short variable linker region, and a 60-amino acid POU-homeo domain. Transactivation of target genes occurs through DNA-dependent and DNA-independent protein-protein interactions, and requires the bipartite POU domain as well as nonconserved sequences outside this domain (14). The POU homeo domain transcription factor Oct-6, also designated SCIP and Tst-1 (15-17), belongs to the intronless class III family of POU factors that, in addition to Oct-6, comprise the closely related genes Brain-1 (Brn-1), Brain-2 (Brn-2), and Brain-4 (Brn-4; 18). Class III POU factors are evolutionarily conserved, and they are expressed predominantly in the nervous system of both mammals and fish $(19,20)$. The Oct-6 locus (designated Otf-6) is located on the distal region of mouse chromosome $4(21,22)$. Expression of the $O c t-6$ gene has been characterized in embryonic stem cells $(16,23)$, early mouse development $(24,25)$, neuronal subpopulations $(17,26,27)$, myelinating glia $(15,28)$, and skin (29). Expression of Oct-6 in both proliferating and postmitotic cells during development indicates that the transcriptional regulating function of the POU factor is complex, and may depend on associations with specific coactivators that bind to either its POU domain or the $\mathrm{NH}_{2}$-terminal transactivation domain (30-34).

The Oct-6 transcription factor is required for an inductive event in Schwann cell development. Expression of Oct-6 is upregulated in Schwann cells associated with axons $(35,36)$, and transgenic mice lacking Oct-6 display a delay in myelination of the PNS after establishing a one-to-one relationship between Schwann cells and axons, indicating that Oct-6 is required for progression of late Schwann cell development $(37,38)$. Contrary to the PNS, Oct-6 does not seem to be essential for myelination of the rodent $\mathrm{CNS}$, perhaps because oligodendrocytes, unlike Schwann cells, express other closely related POU factors (37). However, since Oct-6 expression appears to coincide with the promyelin stage of oligodendrocyte development (39), and pronounced downregulation of Oct- 6 expression accompanies the transition of $\mathrm{O} 2 \mathrm{~A}$ progenitor cells to postmitotic oligodendrocytic cells in culture (28), timely regulation of Oct-6 expression may be important for oligodendrocyte development in vivo. To determine whether or not Oct- 6 conveys a signal that affects myelin formation in oligodendrocytes, we designed a transgenic mouse paradigm in which expression of an Oct-6 transgene was targeted to late oligodendrocyte devel- 
opment. In this study, we show that transgenic mice expressing Oct-6 under transcriptional control of the myelin basic protein (MBP) gene exhibit a developmental defect in myelination of the CNS. These Oct- 6 transgenic mice developed severe neurological disturbances characterized by action tremors, recurrent seizures, and premature death.

\section{Methods}

DNA cloning, transgenic mice, blotting, and PCR analyses. To construct the MBP/Oct-6 transgene, an AvrII-AatII fragment containing a full-length Oct- 6 cDNA, flanked at the $3^{\prime}$ end by SV40 virus early region splice-poly A sequences, was excised from the plasmid pSVOct- $6^{+}(16)$. This DNA fragment was inserted in the $3^{\prime}$ orientation to a 3-kb murine MBP promoter in the Xba1-AatII site of an MBP promoter expression cassette $\mathrm{pNJ}-1$. To generate transgenic mice, the MBP/Oct- 6 transgene was excised from the plasmid backbone by Cla1-AatII digestion, diluted to $6 \mathrm{ng} / \mu \mathrm{l}$ in distilled water, and microinjected into $(\mathrm{C} 57 / \mathrm{BL} 6 \times \mathrm{DBA} / 2) \mathrm{F}_{2}$ zygotes to obtain transgenic $\mathrm{MBP} /$ Oct-6 mice as described elsewhere (40).

Transgenic mice were identified by slot blots, Southern blots, and PCR of DNA samples taken from the tail. For PCR analysis, the following program was used in the thermocycler: one cycle at $96^{\circ} \mathrm{C}$ for 5 $\mathrm{min} ; 30$ cycles $96^{\circ} \mathrm{C}$ for $30 \mathrm{~s}, 55^{\circ} \mathrm{C}$ for $30 \mathrm{~s}, 74^{\circ} \mathrm{C}$ for $3 \mathrm{~min}$, and one cycle at $74^{\circ} \mathrm{C}$ for $8 \mathrm{~min}$. The following primers were used: MBP promoter primer, sense-5' GGG CCC CGC GCG TAA CTG TGC G 3'; and Oct-6 primer, antisense-5' CCT CCG CCT ACC CAA CAC CAC G. Primers to a mouse immunophilin gene muFKBP38 were used as positive controls for the genomic DNA template: sense- $5^{\prime}$ CGG ATG AAG ACA CTG GTC 3' and antisense-5' CAT GAG CGG GAC ACT GAG 3' (K.M. Pedersen and N.A. Jensen, unpublished data).

For Northern blotting, total brain RNA was extracted by the isothiocyanate method (41), electrophoresed in formaldehyde/agarose gels, blotted onto Hybond $\mathrm{N}$ (Amersham International, Little Chalfont, UK) membranes, and hybridized with ${ }^{32} \mathrm{P}$-labeled megaprime (Amersham International) probes.

Histology and electron microscopy. For electron microscopy, the animals were deeply anaesthetized with pentobarbital and transcardially perfused with a phosphate-buffered solution of $1 \%$ glutaraldehyde and $1 \%$ paraformaldehyde $(\mathrm{pH} 7.2)$. The perfused animals were immersed in the same fixative for 2-7 d. Tissue samples were postfixed in $1 \%$ osmium, dehydrated, and embedded in Epon. Ultrathin sections were mounted on mesh grids and stained with uranyl acetate and lead citrate.

For immunohistochemistry, tissue samples were removed from animals perfused with $1 \%$ paraformaldehyde and immersed in a $30 \%$ sucrose solution overnight at $4^{\circ} \mathrm{C}$. The samples were embedded in OCT compound (Tissue Tek; Miles Inc., Elkhart, IN) and frozen with $\mathrm{CO}_{2}$ gas before cryostat sectioning. Tissue sections, $\sim 20 \mu \mathrm{m}$ thick, were collected on glass slides and incubated with $1 \% \mathrm{H}_{2} \mathrm{O}_{2}$ for 3 min to inactivate endogenous peroxidase. After three washes in Hank's buffer, the sections were incubated for $2 \mathrm{~h}$ at $37^{\circ} \mathrm{C}$ with the polyclonal anti-Tst1 antiserum (diluted 1:1,000) in Hank's buffer, washed extensively with Hank's buffer, and incubated for $30 \mathrm{~min}$ at $37^{\circ} \mathrm{C}$ with biotinylated goat anti-rabbit antibodies (DAKO Corp., Carpinteria, CA) diluted (1:400) in Hank's buffer. After extensive washes in Hank's buffer, the sections were incubated for $30 \mathrm{~min}$ in Vectastain Elite ABC peroxidase standard solution (Vector Laboratories, Burlingame, CA), rinsed twice in Hank's buffer, and stained for $15 \mathrm{~min}$ at room temperature using the aminoethylcarbazole substrate kit for horseradish peroxidase (Vector Laboratories). The sections were counterstained with Mayer's hematoxylin and mounted with AquaPoly/Mount (Polysciences, Inc., Warington, PA).

DNA nick end labeling by the terminal deoxynucleotidyltransferase-mediated dUTP-biotin nick end labeling (TUNEL) method. Mice were perfused intracardially with $1 \%$ paraformalde- hyde. The brains were removed, embedded in OCT compound (Tissue Tek), and frozen with $\mathrm{CO}_{2}$ gas. Sections $(10 \mu \mathrm{m})$ were cut with a cryostat microtome and collected on glass slides. To detect cells with fragmented DNA, we used the TUNEL method (42). Tissue sections were air-dried and incubated with $3 \% \mathrm{H}_{2} \mathrm{O}_{2}$ for 5 min at room temperature (RT) to inactivate endogenous peroxidase. The sections were washed three times in Hank's buffer, followed by a single wash in terminal deoxynucleotidyltransferase (TdT) buffer ( $0.5 \mathrm{M}$ cacodylate, $\mathrm{pH} 6.8,1 \mathrm{mM} \mathrm{CoCl} 2,0.5 \mathrm{mM}$ DTT, $0.05 \%$ BSA, $0.15 \mathrm{M} \mathrm{NaCl}$ ), and then incubated for $1 \mathrm{~h}$ at $37^{\circ} \mathrm{C}$ in a moist chamber with $40 \mu \mathrm{M}$ biotin-16-dUTP (Boehringer Mannheim, Mannheim, Germany) and $0.5 \mathrm{U}$ TdT (Boehringer Mannheim) per $\mu \mathrm{l}$ in TdT buffer. After several washes in Hank's buffer, the sections were incubated for $1 \mathrm{~h}$ at $37^{\circ} \mathrm{C}$ in Vectastain elite ABC peroxidase standard solution (Vector Laboratories), rinsed twice in Hank's buffer, and stained for 10 to 15 min at RT using the aminoethylcarbazole substrate kit for horseradish peroxidase (Vector Laboratories). The sections were counterstained with Mayer's hematoxylin and mounted with Aqua-Poly/ Mount (Polysciences, Inc.).

Two-dimensional gel electrophoresis and Western immunoblotting. Two-dimensional gel electrophoresis (15\% acrylamide gels; isoelectrofocusing) and two-dimensional gel Western blots were carried out as described previously $(43,44)$. Optic nerves from agematched affected Oct-6 and control mice were labeled with [35S]methionine, and two-dimensional gel Western blots were prepared. The blots were blocked overnight with $1 \%$ Difco skimmed milk (dehydrated) in Tris-buffered saline, and thereafter were incubated for $2 \mathrm{~h}$ with anti-Tst-1 antiserum $(1: 1,000)$. The immunoreactive proteins were visualized with the enhanced chemiluminescence (ECL) kit from Amersham International.

\section{Results}

Generation and characterization of Oct-6 transgenic mice. A total of seven transgenic mice were generated with a murine Oct-6 transgene under transcriptional control of the MBP promoter (Fig. 1 and Table I). Three MBP/Oct-6 F0 transgenic mice developed action tremors around postnatal day 10 (P10) that progressed to tonic seizures within a few days. One of these F0 transgenics was killed at P22 for Northern blotting. The others died at 3 wk of age, most likely a consequence of seizures. Four founders appeared behaviorally normal, and strains were established from these mice. Heterozygous brother-sister crosses revealed that homozygous mice $(\sim 25 \%)$ of two strains, designated Oc215 and Oc647, developed a neurologic deficit similar to that observed in the affected founders (Table I). No behavioral abnormalities were observed in homozygous progeny of the strain, designated Oc216, implying that these mice expressed subthreshold doses of Oct-6.

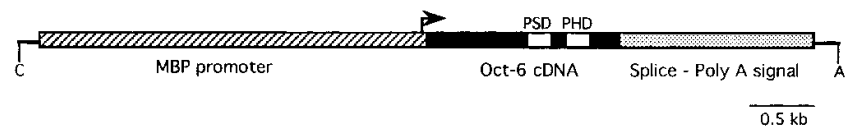

Figure 1. Diagram of the transgenic construct. The MBP/Oct-6 transgene contains a murine MBP promoter (striped box) flanked at the 3' end by a full-length Oct-6 cDNA (black box) and splice-polyadenylation signals from the SV40 virus early region (stippled box). The transcription start site in the MBP promoter is indicated by the arrow. The POU-specific domain (PSD) and the POU-homeo domain $(P H D)$ in the Oct-6 gene are indicated by white boxes. The transgene containing Cla1-AatII fragment of pMBP/Oct- 6 was isolated from vector sequences and microinjected into fertilized mouse eggs to produce transgenic Oct-6 mice. 
Table I. Summary of MBP/Oct-6 Transgenic Mice

\begin{tabular}{|c|c|c|c|c|c|}
\hline Founder & $\begin{array}{c}\text { Neurologic } \\
\text { deficit }^{\S}\end{array}$ & Onset & $\begin{array}{l}\text { Heterozygous } \\
\text { intercross }\end{array}$ & $\begin{array}{c}\text { Neurologic } \\
\text { deficit }^{\S}\end{array}$ & Onset \\
\hline & & $\begin{array}{c}\text { post- } \\
\text { natal d }\end{array}$ & $\begin{array}{c}\% \text { offspring with } \\
\text { neurologic } \\
\text { deficit }\end{array}$ & & $\begin{array}{c}\text { post- } \\
\text { natal d }\end{array}$ \\
\hline Oc $5^{*}$ & $\mathrm{~T}, \mathrm{~S}^{\mathrm{I}}$ & P10 & & & \\
\hline Oc $9 *$ & $\mathrm{~T}, \mathrm{~S}^{\mathrm{q}}$ & P10 & & & \\
\hline Oc $10^{*}$ & $\mathrm{~T}, \mathrm{~S}^{\mathbb{I}}$ & P10 & & & \\
\hline \multicolumn{6}{|l|}{ Oc $42^{\ddagger}$} \\
\hline Oc 215 & & & $23(n=28)$ & $\mathrm{T}, \mathrm{S}^{\mathrm{T}}$ & P10 \\
\hline Oc 216 & & & $0(n=40)$ & & \\
\hline Oc 647 & & & $21(n=24)$ & $\mathrm{T}, \mathrm{S}, \mathrm{A}^{\mathrm{q}}$ & P10 \\
\hline
\end{tabular}

*Indicates no offspring. ${ }^{*}$ Indicates no transgenic offspring. ${ }^{\S} \mathrm{T}$, action

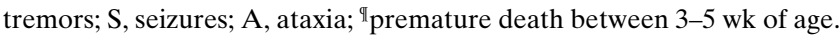

The region of the mouse MBP gene used to control expression of the Oct- 6 transgene has previously been shown to be sufficient to direct oligodendrocyte-specific transcription in the CNS of transgenic mice (40). In sagittal sections of the cerebellum of Oct- 6 transgenic mice stained with an Oct- 6 antibody, expression of the transgene appeared predominantly in the white matter (Fig. 2). Only a few Oct-6-positive cells were observed in the neuron-rich granule cell layer and molecular layer of the cerebellum of the transgenic mice. This expression pattern is consistent with oligodendrocyte-specific expression of the transgene.

Because Oct- 6 is believed to act as a repressor of MBP gene expression $(45,46)$, we investigated with Northern blots whether or not affected Oct-6 transgenic mice expressed reduced levels of mRNA that encoded the major myelin proteins $\mathrm{MBP}$ and proteolipid protein (PLP) in the CNS (Fig. $3 A$ ). For positive controls, we used tissue specimens from transgenic mice expressing an activated c-myc oncogene under transcriptional control of the MBP gene (47). These mice exhibit pronounced pathologic degeneration of oligodendroglia during myelination of the CNS and, accordingly, reduced expression signals of both MBP and PLP mRNAs. As opposed to MBP/ c-myc transgenic mice, affected MBP/Oct-6 transgenics expressed MBP and PLP mRNAs at levels comparable to those of nontransgenic controls (Fig. $3 A$ ), suggesting that Oct-6 is not directly involved in transcriptional regulation of these genes in oligodendroglia. Furthermore, they suggest that the pathogenesis of the myelin deficiency in the Oct- 6 mice is distinct from that in the $\mathrm{MBP} / \mathrm{c}-m y c$ mice.

To investigate whether programmed cell death could play a role in the pathogenesis of dysmyelination in the Oct- 6 mice, we compared the extent of TUNEL staining in sagittal brain sections from age-matched affected MBP/Oct-6 and MBP/ c-myc mice (Fig. 4). Contrary to $\mathrm{MBP} / \mathrm{c}-m y c$ transgenic mice (47), the number of TUNEL-positive nuclei in affected MBP/ Oct- 6 transgenics was comparable to that of age-matched nontransgenic controls during active CNS myelination. The more or less normal levels of programmed cell death (as measured by TUNEL staining) in the brains of Oct- 6 transgenics indicate that Oct-6, in contrast to c-myc, is not cytotoxic to developing oligodendroglia.

Because diseased Oct- 6 transgenic mice appeared to ex-
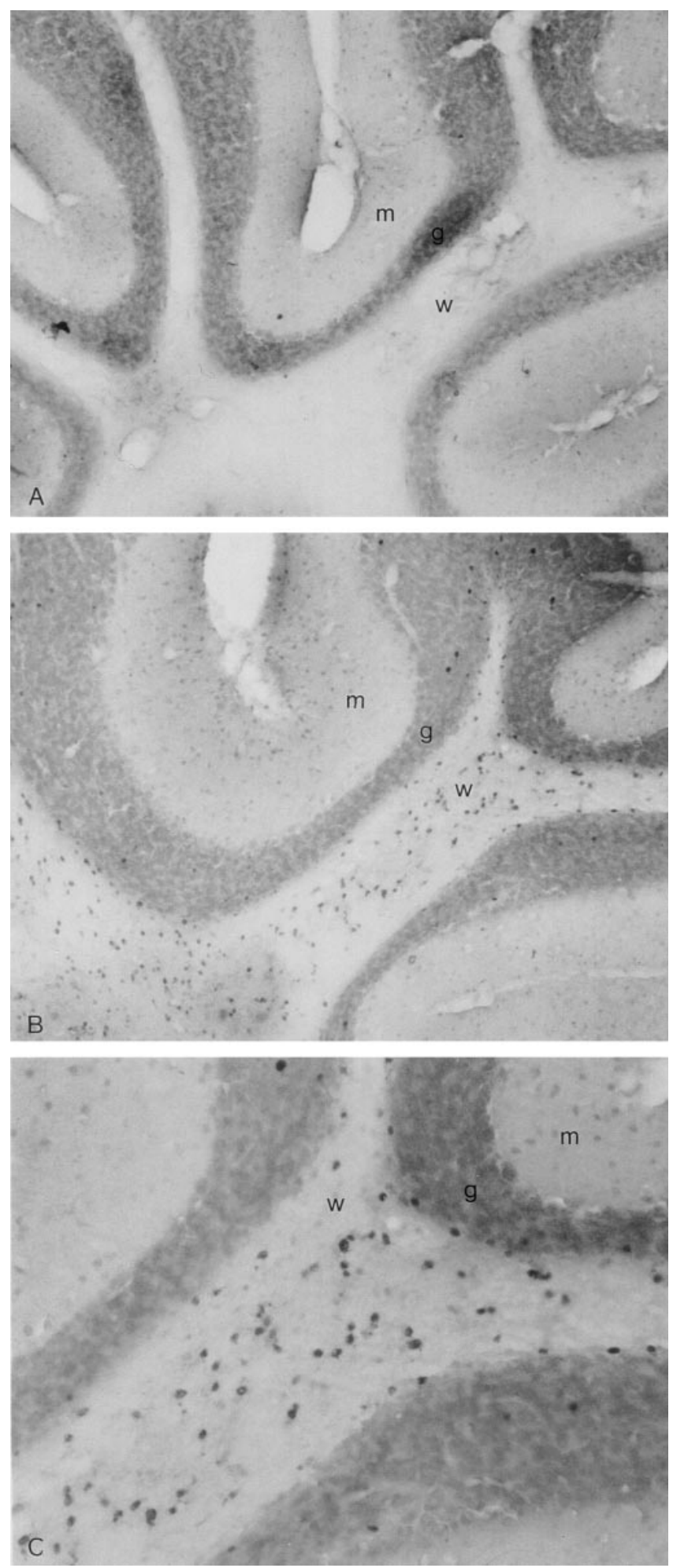

Figure 2. Immunohistochemical localization of Oct-6 in transgenic mice. Light micrographs of sagittal sections through the cerebellum of a nontransgenic control $(A)$ and an affected Oct-6 transgenic mouse ( $B$ and $C$ ) at P24. The Oct-6-positive nuclei are the dark rounded objects confined predominantly to the white matter $(w)$ region of a folium $(B$ and $C$ ). Only a few Oct-6-positive cells appeared in the neuron-rich granule layer $(\mathrm{g})$ and the molecular layer $(\mathrm{m})$ of the transgenic mice $(B$ and $C$ ), which is consistent with the oligodendrocyte-specific expression of the transgene. No Oct-6 expression was detected in white matter $(w)$, granule layer $(g)$, and molecular layer $(m)$ of control animals $(A)$. A, B, 340×; C, 680×. 


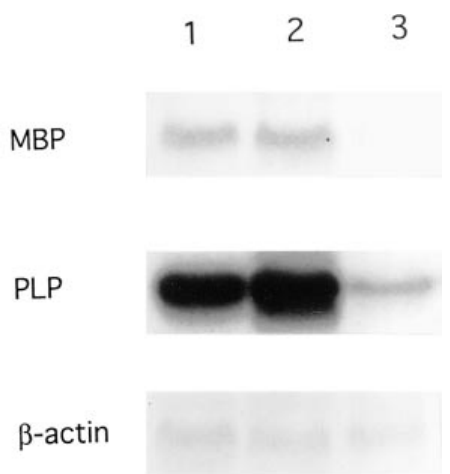

A

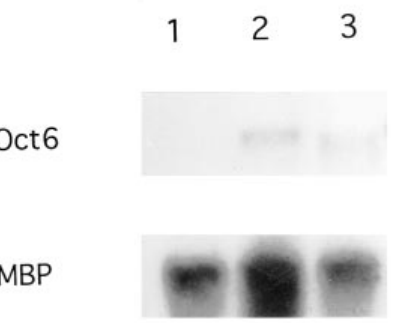

B
Figure 3. (A) Northern blot analysis of myelin structural gene expression in the brains of transgenic mice. Total brain RNA from an affected Oct- 6 transgenic mouse (lane 1), a nontransgenic control (lane 2 ), and a c-myc transgenic mouse (lane 3), was isolated from $\mathrm{P} 23$ animals and used in successive hybridizations with MBP, PLP, and $\beta$-actin probes as indicated. Note the markedly reduced expression of MBP and PLP in the c-myc transgenic mouse. Hybridization with the $\beta$-actin probe indicates relative amounts of total RNA (10 $\mu$ g per lane). (B) Northern blot analysis of Oct- 6 gene expression in the brains of transgenic mice. Total RNA from a nontransgenic control (lane 1)

and from affected Oct-6 mice from strain Oc215 (lane 2) and strain Oc647 (lane 3) was isolated from P21 animals and used in successive hybridizations with Oct- 6 and MBP hybridization probes. Hybridization with the MBP probe indicates relative amounts of total RNA (10 $\mu \mathrm{g}$ per lane).

press normal levels of MBP and PLP mRNAs, we used electron microscopy to determine if myelination of the CNS was affected in the transgenic mice. As shown in Fig. 5, axons in the optic nerves of affected Oct- 6 transgenic mice were abnormally myelinated in that the internodes were hypomyelinated, hypermyelinated, and dysmyelinated. One notable feature of the myelin deficiency in the Oct- 6 transgenics was the presence of numerous large axons that lacked a myelin covering, as seen in the low-power electron micrographs shown in Fig. 5, $C, F$, $G$, and $H$. Morphologically distinct myelin structures appeared frequently in optic nerves of affected animals. The term serpentine myelin was used to characterize myelin processes that appeared either in the absence of definite axonal association (Fig. 5, $D$ and $F$ ), or in association with more than one internode (Fig. 5, $D-G$ ). In addition, numerous internodes harbored myelin sheaths that were disproportionally thick for the diameter of the axon with which they were associated (Fig. 5, $D-G)$, and concentric layering of myelin was often disrupted as shown in Fig. 5, $D-F$. Extraordinarily large myelin aggregates in which axons were absent were occasionally observed (Fig. $5 \mathrm{H}$ ). PNS myelination in the Oct-6 transgenic mice appeared to be normal.

Because the optic nerve is highly enriched in myelin-forming oligodendroglia, we performed two-dimensional gel Western blots to evaluate the level of Oct-6 protein expression in optic nerves from affected Oct-6 transgenic mice. Weak stain- ing of Oct- 6 proteins appeared in optic nerve specimens from affected Oct-6 animals, but not in the controls (Fig. 6). The major proteins recognized with the anti-Tst- 1 antibody have apparent relative masses of $\sim 53 \mathrm{kD}$ and a $\mathrm{pI}$ of $\sim 7.1$ (Fig. 6). The relative masses are consistent with that seen in $\mathrm{O} 2 \mathrm{~A}$ progenitor cells (28), and the $\mathrm{pI}$ is similar to that predicted for Oct-6 ( $\mathrm{pI}=7.0)$. In addition, low to moderate levels of Oct-6 expression were consistently observed in Northern blots of total RNA purified from the brains of affected Oct- 6 transgenic animals from distinct strains (Fig. 3 B). Taken together, these data suggest that the myelin deficiency observed in the CNS of affected animals results from moderate overexpression of the transgene, although we cannot definitively rule out the possibility that a subpopulation of oligodendroglia expresses high doses.

\section{Discussion}

During CNS myelination, oligodendrocyte precursor cells cease to proliferate, differentiate into multiprocess-bearing cells, and initiate myelin synthesis and assembly after establishing axoglial junctions (48). Although myelin formation can occur in the absence of neurons in cultured oligodendroglia (49-51), recent evidence suggests that a signal conveyed from the axolemma to the oligodendroglia plays an important role in coordinating myelin assembly in the CNS (52). During PNS myelination, expression of the homeo domain transcription factor Oct-6 in Schwann cells is upregulated by axons (35), and mice lacking Oct-6 exhibit delayed myelination after establishing a one-to-one relationship between Schwann cells and large

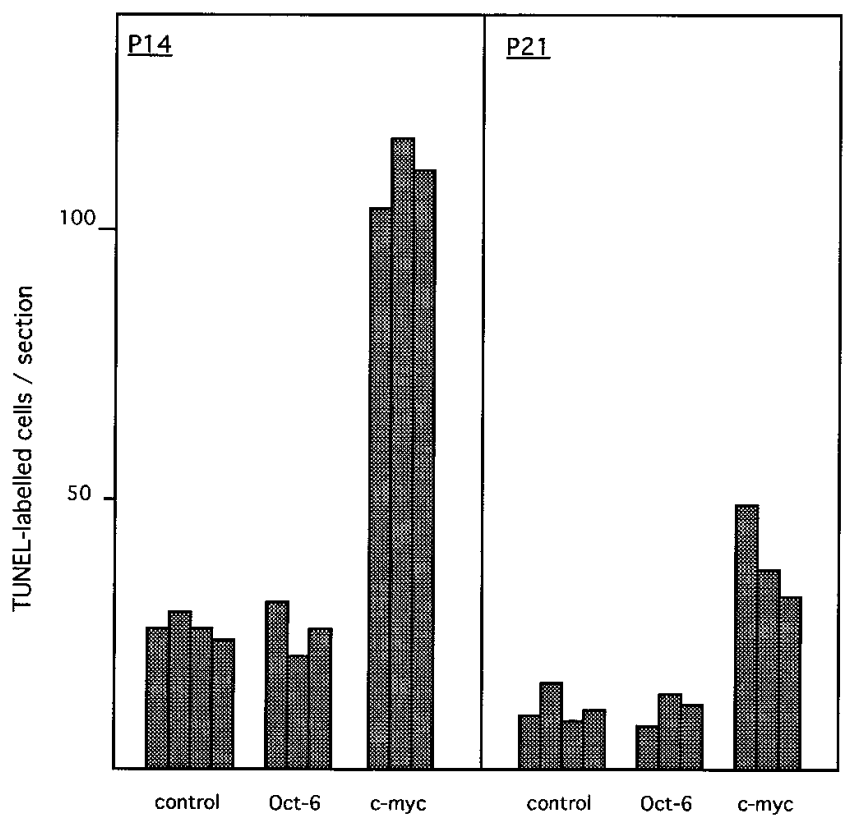

Figure 4. Examination of oligodendrocyte degeneration with TUNEL labeling. Graphic representation of the number of TUNEL-labeled cells observed in three to four matched sagittal sections, $\sim 1 \mathrm{~mm}$ from the midline of the brains of a nontransgenic control mouse and affected homozygous Oct- 6 and c-myc transgenic mice. The counts are shown for one individual of each of the three types of mice at P14 and P21. 

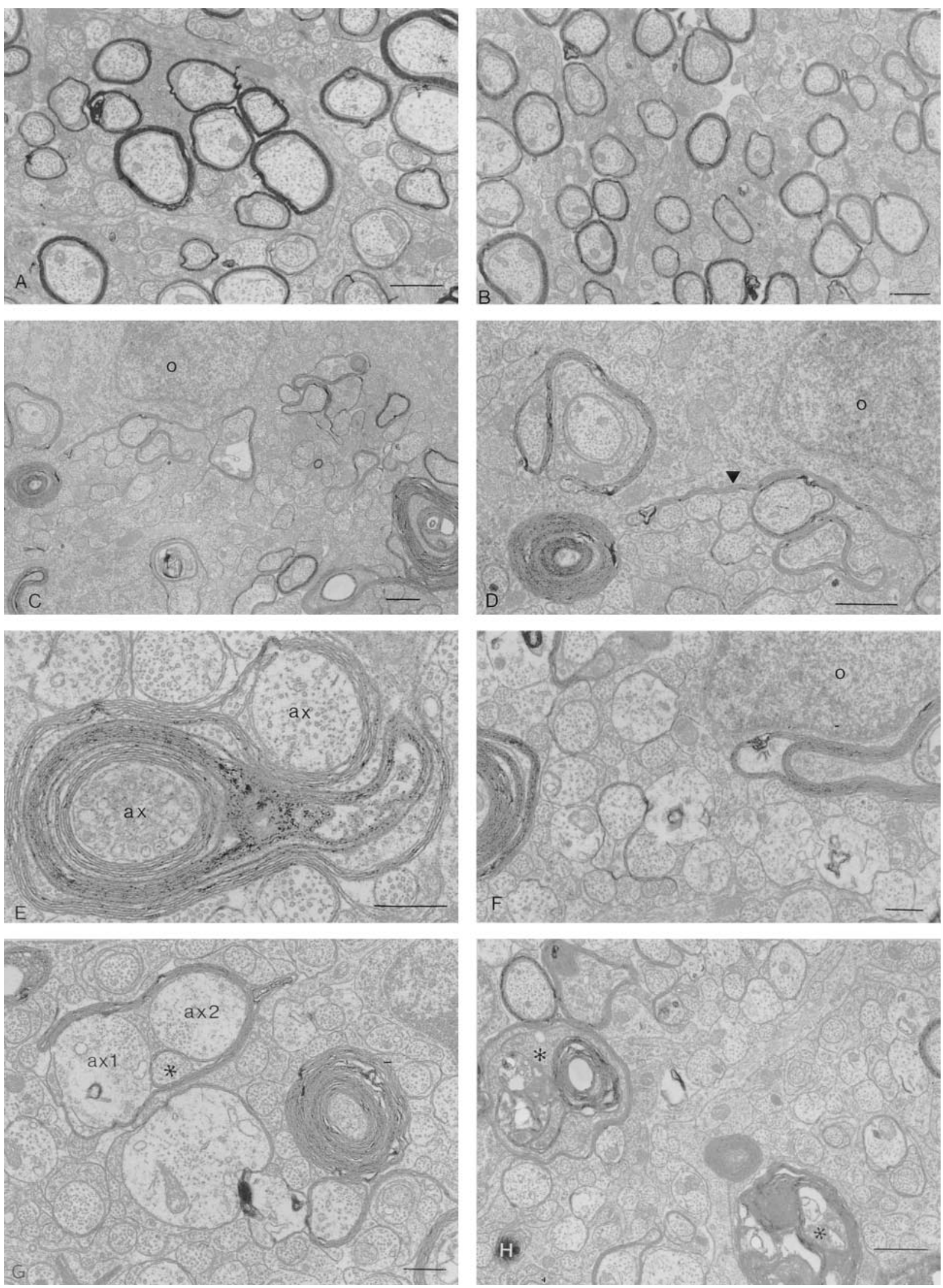

Figure 5. Electron micrographs of optic nerves from age-matched control and Oct-6 transgenic mice. $(A)$ A nontransgenic control showing the normal pattern of myelination. $(B)$ an unaffected Oct-6 transgenic heterozygote displaying normal myelinization. $(C-H)$ An affected Oct-6 transgenic mouse that displayed severe action tremors and recurrent seizures. $(C)$ Low magnification micrograph showing pronounced hypomyelinization and abnormal myelin profiles. A large abnormal myelin aggregate is apparent at the lower right corner ( $o$; oligodendrocyte). $(D)$ higher magnification of the left part of $C$, showing a serpentine myelin profile (dark arrowhead) in the parenchyma adjacent to an oligodendro- 


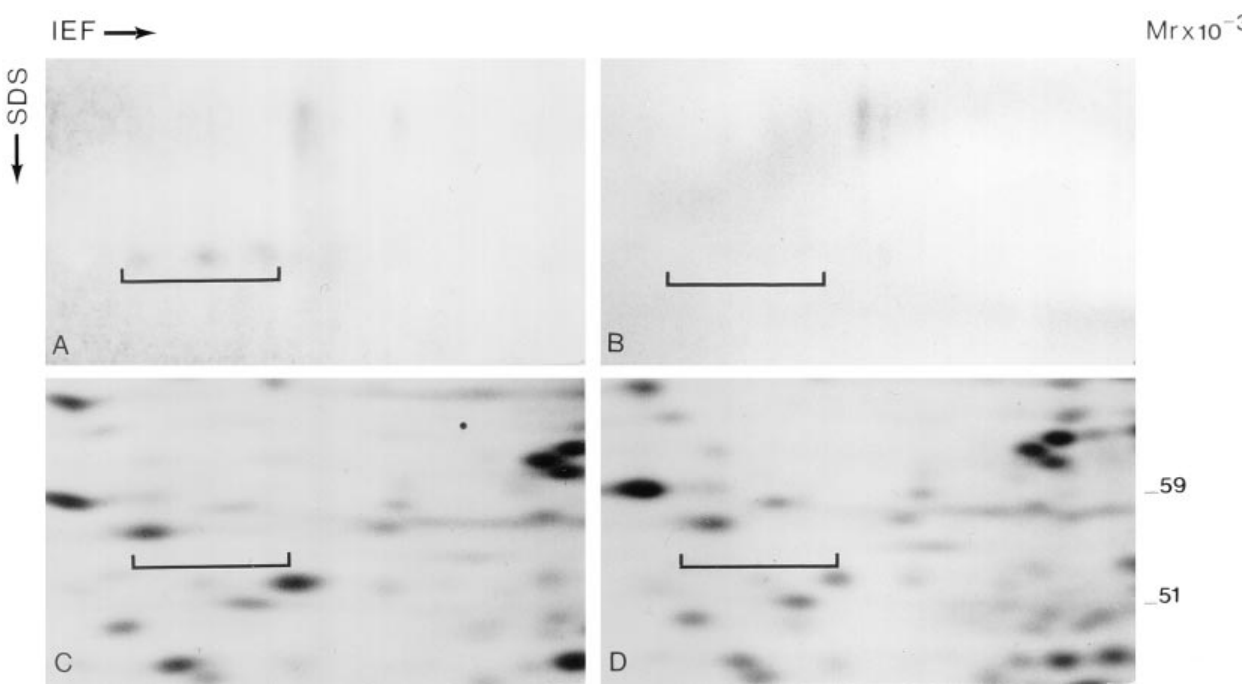

Figure 6. Two-dimensional gel Western blot analysis of Oct- 6 expression in the optic nerves of transgenic mice. Immunoblots and twodimensional gels of optic nerves from affected Oct-6 $(A$ and $C)$ and nontransgenic control $(B$ and $D)$ P20 animals. The immunoblots $(A$ and $B$ ) were reacted with anti-Tst-1 antiserum. The location of the Oct-6 proteins, recognized by the Tst- 1 antibody, is shown in brackets. $(C$ and $D$ ) show the appropriate region of autoradiograms of [35S]-labeled optic nerve proteins. axons $(37,38)$. Taken together, these results suggest that Oct- 6 plays an important role in coordinating myelin synthesis in Schwann cells.

In the present study, we used a gain-of-function transgenetic approach to investigate whether or not overexpression of Oct-6 at late oligodendrocyte development affects myelination in the CNS. The rationale behind these experiments was based on the previous finding that Oct- 6 is expressed transiently in promyelin oligodendroglial cells, and that it is downregulated during the transition of these cells to postmitotic myelin-forming cells (28). Accordingly, it was hypothesized that transient expression of the POU factor during oligodendrocyte development has functional consequences, and that deregulated expression of Oct- 6 could interfere with normal development of these cells in vivo. The finding in this report of a structural myelin defect associated with Oct- 6 overexpression in oligodendroglia in vivo indicates that developmental regulation of Oct-6 expression is important for normal assembly of myelin in the CNS, and that deregulated expression of the POU factor could play a role in pathogenesis of myelin disease.

Transgenic progeny from two founders and three $\mathrm{F}_{0}$ transgenic mice developed similar phenotypes, characterized by action tremors, recurrent seizures, and premature death. Premature death of the animals was most probably a consequence of defective myelination in the CNS and concomitant seizures. The observed deposition of abnormal myelin in the CNS of MBP/Oct- 6 mice seems to contradict the arrested myelination observed in Oct-6 knockouts $(37,38)$. Notable features of the myelin defect in the MBP/Oct- 6 mice, described in the present study, included serpentine myelin profiles, internodes harboring multiple myelin sheaths, disruption of the concentric layering of myelin, and accumulation of large myelin aggregates in the parenchyma. The presence of groups of axons that were occasionally wrapped by a single sheath of serpentine myelin suggests that formation of myelin in the MBP/Oct- 6 mice was premature, and occurred before establishment of the axo-glial junction. In Schwann cells, Oct-6 has been reported to be involved in a differentiation pathway that is activated by axons (35). Assuming that the POU factor possesses a similar function in oligodendroglia, overexpression of Oct- 6 in these cells could preempt or mimic axo-glial communication and trigger abnormal myelination. In addition, the presence of normal levels of MBP and PLP mRNA in the brains of affected Oct-6 transgenic mice argues against a direct role for the POU factor in transcriptional regulation of the major myelin genes in oligodendroglia. The latter fact is consistent with the observation that the lack of Oct- 6 does not appear to affect expression of the major myelin genes in Schwann cells of Oct-6 knockout mice (37).

A pronounced feature of the Oct- 6 transgenic model, described in the present study, is that the central myelin defects in the MBP/Oct-6 mice displayed many of the characteristics of those observed in the PNS of transgenic mice expressing a truncated Oct-6 transgene (designated $\Delta$ SCIP) in Schwann cells (46). This feature implies that the two transgenes may interfere with myelination in similar ways. Overexpression of

\section{Figure 5 legend (Continued)}

cyte. Note the continuity between this process, the abnormal myelin process to the far right, and the cytoplasm of the oligodendrocyte. At the lower part to the left is seen a hypermyelinated internode containing multiple individual sheaths of myelin. $(E)$ two axons $(a x)$ associated with abnormal myelin profiles. The axon to the left is encased in more than one sheath, and is surrounded by a serpentine myelin process extending from the axon on the right. $(F)$ An abnormal myelin profile adjacent to an oligodendrocyte in which the concentric layering of myelin is interrupted. Note the inverted S-shaped serpentine myelin process in the middle left of the picture that is associated with two adjacent axons, and the hypermyelinated internode to the far left displaying at least three layers of individual myelin sheaths. $(G)$ A serpentine myelin sheath associated with three adjacent axons (designated by $\mathrm{a} \times 1, \mathrm{a} \times 2$, and *). Note the hypermyelinated internode adjacent to a large axon in the middle of the picture. $(H)$ Two large myelin aggregates, left and bottom right (*), without any obvious contact with an axon. Bars, $1 \mu \mathrm{m}(A, C, D$, and $H) ; 0.5$ $\mu \mathrm{m}(B, E, F$, and $G)$. 
$\Delta$ SCIP during late Schwann cell development resulted in hypermyelination of internodes, multiaxon bundles being surrounded by a single myelin sheath, and myelin synthesis in the absence of axonal contact. The phenotype in the $\Delta$ SCIP mice was consistent with the precocious differentiation of myelinforming Schwann cells (46). The $\Delta$ SCIP transgene has a 140 amino acid deletion in the amino-terminal region of rat Oct-6 (termed SCIP), and the transgene was assumed to antagonize competively the wild-type Oct-6 function. This interpretation of $\Delta$ SCIP activity and its pronounced positive effect on myelin synthesis in vivo, however, are difficult to reconcile with the observation that lack of Oct-6 blocks and/or delays peripheral myelination in vivo $(37,38)$. Overexpression of a partially functional $\Delta$ SCIP transgene during late Schwann cell development could result in a gain-of-function effect similar to the one described in this report. We found no gross anatomical defects in myelination of the PNS in the MBP/Oct-6 transgenic mice, perhaps due to lack of regulatory elements for Schwann cell expression in the MBP promoter (53).

In addition to its role in myelin formation, axo-glial interaction also appears to play a crucial role in promoting oligodendrocyte survival during development $(54,55)$. Although myelination was abnormal in the Oct-6 mice, there was no indication of pathologic oligodendrocyte cell death, as judged from TUNEL staining and electron microscopy. This result suggests that hypomyelination in the MBP/Oct-6 mice is not related to a Oct-6-induced cytotoxicity in oligodendroglia during the period of active myelin-formation, as was previously observed in transgenic mice overexpressing a human c-myc transgene during late oligodendrocyte development (47).

Taken together, this study provides evidence that downregulation of Oct-6 gene expression in late oligodendrocyte development is crucial for myelin formation, and it supports the notion that deregulated expression of the POU factor could be involved in the molecular pathogenesis of severe human myelin diseases, such as progressive multifocal leukoencephalopathy $(56,57)$ and multiple sclerosis $(58)$.

\section{Acknowledgments}

The authors thank A.M. Bønsdorf, B. Andersen, D. Jensen, A. Meier for expert technical assistance, Dr. M. Wegner for the gift of rabbit anti-Tst1 antiserum, and Dr. P. Gruss for providing the plasmid pSVOct6 $^{+}$.

These investigations were supported by grants from the Danish Medical Research Council, the Danish Cancer Society, the Alfred Benzon Foundation, the NOVO-Nordisk Foundation, the Multiple Sclerosis Society of Denmark, and the ADRC at Johns Hopkins University Medical School.

\section{References}

1. Raine, C.S. 1984. Morphology of myelin and myelination. In Myelin. P. Morell, editor. Plenum Publishing Corporation, New York. 1-50.

2. Pfeiffer, S.E., A.E. Warrington, and R. Bansal. 1993. The oligodendrocyte and its many cellular processes. Trends Cell Biol. 3:191-197.

3. Morell, P., R.H. Quarles, and W.T. Norton. 1994. Myelin formation, structure, and biochemistry. In Basic Neurochemistry: Molecular, Cellular, and Medical Aspects. G.J. Siegel, B.W. Agranoff, R.W. Albers, and P.B. Molinoff, editors. Raven Press, Ltd., New York. 117-143.

4. Campagnoni, A.T. 1995. Molecular biology of myelination. In Neuroglia. H. Kettenman and B.R. Ransom, editors. Oxford University Press, New York. $555-570$.

5. Rosenbluth, J. 1995. Glial membranes and axoglial junctions. In Neuroglia. H. Kettenman and B.R. Ransom, editors. Oxford University Press, New
York. 613-633.

6. Szuchet, S. 1995. The morphology and ultrastructure of oligodendrocytes and their functional implications. In Neuroglia. H. Kettenman and B.R. Ransom, editors. Oxford University Press, New York. 23-43.

7. Remahl, S., and C. Hildebrand. 1990. Relation between axons and oligodendroglial cells during initial myelination. J. Neurocytol. 19:313-328.

8. Butt, A.M., and B.R. Ransom. 1993. Morphology of astrocytes and oligodendrocytes during development in the intact rat optic nerve. J. Comp. Neurol. 338:141-158.

9. Bunge, R.P., and C. Fernandez-Valle. 1995. Basic biology of the Schwann cell. In Neuroglia. H. Kettenman and B.R. Ransom, editors. Oxford University Press, New York. 44-57.

10. Mirsky, R., and K.R. Jessen. 1996. Schwann cell development, differentiation and myelination. Curr. Opin. Neurobiol. 6:89-96.

11. Ruvkun, G., and M. Finney. 1991. Regulation of transcription and cell identity by POU domain proteins. Cell. 64:475-478.

12. Rosenfeld, M.G. 1991. POU-domain transcription factors: Pou-er-ful developmental regulators. Genes. Dev. 5:897-907.

13. Schöler, H.R. 1991. Octamania: the POU factors in murine development. Trends Genet. 7:323-329.

14. Herr, W., and M.A. Cleary. 1995. The POU domain: versatility in transcriptional regulation by a flexible two-in-one DNA-binding domain. Genes Dev. 9:1679-1693

15. Monuki, E.S., G. Weinmaster, R. Kuhn, and G. Lemke. 1989. SCIP: a glial POU domain gene regulated by cyclic AMP. Neuron. 3:783-793.

16. Suzuki, N., H. Rohdewohld, T. Neuman, P. Gruss, and H.R. Schöler. 1990. Oct-6: a POU transcription factor expressed in embryonal stem cells and in the developing brain. EMBO (Eur. Mol. Biol. Organ) J. 9:3723-3732.

17. He, X., R. Gerrero, D.M. Simmons, R.E. Park, C.J. Lin, L.W. Swanson, and M.G. Rosenfeld. 1991. Tst-1, a member of the POU domain gene family, binds the promoter of the gene encoding the cell surface adhesion molecule Po. Mol. Cell. Biol. 11:1739-1744.

18. Hara, Y., A.C. Rovescalli, Y. Kim, and M. Nirenberg. 1992. Structure and evolution of four domain genes expressed in mouse brain. Proc. Natl. Acad. Sci. USA. 89:3280-3284.

19. He, X., M.N. Treacy, D.M. Simmons, H.A. Ingraham, L.W. Swanson, and M.G. Rosenfeld. 1989. Expression of a large family of POU-domain regulatory genes in mammalian brain development. Nature. 340:501-506.

20. Spaniol, P., C. Bornmann, G. Hauptmann, and T. Gerster. 1996. Class III POU genes of zebrafish are predominantly expressed in the central nervous system. Nucleic Acids Res. 24:4874-4881.

21. Rohdewohld, H., and P. Gruss. 1992. The gene for the POU domain transcription factor Oct-6 maps to the distal end of mouse chromosome 4. Mamm. Genome. 3:119-121.

22. Avraham, K.B., B.C. Cho, D. Gilbert, H. Fuji, K. Okamoto, T. Shimazaki, T. Ito, H. Shoji, Y. Wakamatzu, H. Kondoh, et al. 1993. Murine chromosomal location of four class III POU transcription factors. Genomics. 18: $131-133$.

23. Meijer, D., A. Graus, R. Kraay, A. Langeveld, M.P. Mulder, and G. Grosveld. 1990. The octamer binding factor Oct-6: cDNA cloning and expression in early embryonic cells. Nucleic Acids Res. 9:2241-2247.

24. Abdel-Rahman, B., M. Fiddler, D. Rappolee, and E. Pergament. 1995. Expression of transcription regulating genes in human preimplantation embryos. Hum. Reprod. 10:2787-2792.

25. Zwart, R., L. Broos, G. Grosveld, and D. Meijer. 1996. The restricted expression pattern of the POU factor Oct-6 during early development of the mouse nervous system. Mech. Dev. 54:185-194.

26. Frantz, G.D., A.P. Bohner, R.M. Akers, and S.K. McConnell. 1994 Regulation of the POU domain gene SCIP during cerebral cortical development. J. Neurosci. 14:472-485.

27. Alvarez-Bolado, G., M.G. Rosenfeld, and L.W. Swanson. 1995. Model of forebrain regionalization based on spatiotemporal patterns of POU-III homeobox gene expression, birthdates, and morphological features. J. Comp. Neurol. 355:237-295.

28. Collarini, E.J., R. Kuhn, C.J. Marshall, E.S. Monuki, G. Lemke, and W.D. Richardson. 1992. Down-regulation of the POU transcription factor SCIP is an early event in oligodendrocyte differentiation in vitro. Development. 116 : 193-200.

29. Faus, I., H.-J. Hsu, and E. Fuchs. 1994. Oct-6: A regulator of keratinocyte gene expression in stratified squamous epithelia. Mol. Cell. Biol. 14: 3263-3275.

30. Meijer, D., A. Graus, and G. Grosveld. 1992. Mapping the transactivation domain of the Oct-6 POU transcription factor. Nucleic Acids Res. 20:22412247.

31. Monuki, E.S., R. Kuhn, and G. Lemke. 1993. Repression of the myelin Po gene by the POU transcription factor SCIP. Mech. Dev. 42:15-32.

32. Renner, K., H. Leger, and M. Wegner. 1994. The POU-domain protein Tst-1 and papovaviral T-antigen function synergistically to stimulate glia-specific gene expression of JC virus. Proc. Natl. Acad. Sci. USA. 91:6433-6437.

33. Leger, H., E. Sock, K. Renner, F. Grummt, and M. Wegner. 1995. Functional interaction between the POU domain protein Tst-1/oct-6 and the highmobility-group protein HMG-I/Y. Mol. Cell. Biol. 15:3738-3747. 
34. Wegner, M., D.W. Drolet, and M.G. Rosenfeld. 1993. POU-domain proteins: structure and function of developmental regulators. Curr. Opin. Cell Biol. 5:488-498.

35. Scherer, S.S., D.-Y. Wang, R. Kuhn, G. Lemke, L. Wrabetz, and J. Kamholz. 1994. Axons regulate Schwann cell expression of the POU transcription factor SCIP. J. Neurosci. 14:1930-1942.

36. Blanchard, A.D., A. Sinanan, E. Parmantier, R. Zwart, L. Broos, D. Meijer, C. Meier, K.R. Jessen, and R. Mirsky. 1996. Oct-6 (SCIP/Tst-1) is expressed in Schwann cell precursors, embryonic Schwann cells, and postnatal myelinating Schwann cells: comparison with Oct-1, Krox-20, and Pax-3. J. Neurosci. Res. 46:630-640.

37. Bermingham, J.R., S.S. Scherer, S. O'Connell, E. Arroyo, K.A. Kalla, F.L. Powell, and M.G. Rosenfeld. 1996. Tst-1/Oct-6/SCIP regulates a unique step in peripheral myelination and is required for normal respiration. Genes Dev. 10:1751-1762.

38. Jaegle, M., W. Mandemakers, L. Broos, R. Zwart, A. Karis, P. Visser, F. Grosveld, and D. Meijer. 1996. The POU factor Oct-6 and Schwann cell differentiation. Science. 273:507-510.

39. Bögler, O., A. Entwistle, R. Kuhn, E. Monuki, G. Lemke, and M. Noble. 1993. Single cell analysis of the expression of a nuclear protein, SCIP, by fluorescent immunohistochemistry visualized with confocal microscopy. Histochem. J. 25:746-761.

40. Jensen, N.A., G.M. Smith, H.D. Shine, J.S. Garvey, and L. Hood. 1993. Distinct hypomyelinated phenotypes in MBP-SV40 large T transgenic mice. $J$. Neurosci. Res. 34:257-264.

41. Chirgwin, J.M., A.E. Przybyla, R.J. MacDonald, and W.J. Rutter. 1979. Isolation of biologically active ribonucleic acid from sources enriched in ribonuclease. Biochemistry. 18:5294-5299.

42. Gavrieli, Y., Y. Sherman, and S.A. Ben-Sasson. 1992. Identification of programmed cell death in situ via specific labeling of nuclear DNA fragmentation. J. Cell Biol. 119:493-501.

43. Celis, J.E., J.B. Lauridsen, and B. Basse. 1997. Determination of antibody specificity by Western blotting and immunoprecipitation. In Cell Biology: A Laboratory Handbook (Vol. 2). J.E. Celis, N.P. Carter, T. Hunter, D.M. Shotton, K. Simons, and J.V. Small, editors. Academic Press, Inc., San Diego. 429-437.

44. Celis, J.E., G. Ratz, B. Basse, J.B. Lauridsen, A. Celis, N.A. Jensen, and P. Gromov. 1997. High-resolution two-dimensional gel electrophoresis of proteins: isoelectric focusing (IEF) and nonequilibrium $\mathrm{pH}$ gradient electrophoresis (NEPHGE). Applications to the analysis of cultured cells and mouse knockouts. In Cell Biology: A Laboratory Handbook (Vol. 4). J.E. Celis, N.P. Carter, T. Hunter, D.M. Shotton, K. Simons, and J.V. Small, editors. Academic Press, Inc., San Diego. 375-385.
45. Monuki, E.S., R. Kuhn, G. Weinmaster, B.D. Trapp, and G. Lemke. 1990. Expression and activity of the transcription factor SCIP. Science. 249: $1300-1303$.

46. Weinstein, D.E., P.G. Burrola, and G. Lemke. 1995. Premature Schwann cell differentiation and hypermyelination in mice expressing a targeted antagonist of the POU transcription factor SCIP. Mol. Cell. Neurosci. 6: 212-229.

47. Jensen, N.A., K.M. Pedersen, J.E. Celis, and M.J. West. 1998. Failure of central nervous system myelination in $\mathrm{MBP} / \mathrm{c}-m y c$ transgenic mice: Evidence for c-myc cytotoxicity. Oncogene. In Press.

48. Waxman, S.G., and J.A. Black. 1995. Axoglial interactions at the cellular and molecular levels in central nervous system myelinated fibers. In Neuroglia. H. Kettenman and B.R. Ransom, editors. Oxford University Press, New York. 587-610.

49. Bradel, E.J., and F.P. Price. 1983. Cultured neonatal rat oligodendrocytes elaborate myelin membrane in the absence of neurons. J. Neurosci. Res. 9: 381-392.

50. Rome, L.H., P.N. Bullock, F. Chiappelli, M. Cardwell, A.M. Adinoff, and D. Swanson. 1986. Synthesis of a myelin-like membrane by oligodendrocytes in culture. J. Neurosci. Res. 15:49-65.

51. Knapp, P.E., W.P. Bartlett, and R.P. Skoff. 1987. Cultured oligodendrocytes mimic in vivo phenotypic characteristics: cell shape, expression of myelin antigens, and membrane production. Dev. Biol. 120:356-365.

52. Notterpek, L.M., and L.H. Rome. 1994. Functional evidence for the role of axolemma in CNS myelination. Neuron. 13:473-485.

53. Gow, A., V.L. Friedrich, and R.A. Lazzarini. 1992. Myelin basic protein gene contains separate enhancers for oligodendrocyte and Schwann cell expression. J. Cell Biol. 119:605-616.

54. Raff, M.C., B.A. Barres, J.F. Burne, S.H. Coles, Y. Ishizaki, and M.D. Jacobson. 1993. Programmed cell death and the control of cell survival: lessons from the nervous system. Science. 262:695-700.

55. Barres, B.A., and M. Raff. 1996. Axonal control of oligodendrocyte development. In Glial Cell Development. K.R. Jessen and W.D. Richardson, editors. BIOS Scientific Publishers Limited, Oxford, United Kingdom. 71-83.

56. Wegner, M., D.W. Drolet, and M.G. Rosenfeld. 1993. Regulation of JC virus by the POU-domain transcription factor Tst-1: implications for progressive multifocal leukoencephalopathy. Proc. Natl. Acad. Sci. USA. 90:4743-4747.

57. Renner, K., E. Sock, J.K. Gerber, and M. Wegner. 1996. T antigen of human papovavirus JC stimulates transcription of the POU domain factor Tst1/Oct-6/SCIP. DNA Cell Biol. 15:1057-1062.

58. Kamholz, J.A. 1996. Regulation of myelin development. Mult. Scler. 2: $236-240$. 